\title{
JUVENTUDE E PROTAGONISMO: CATEGORIA TEÓRICA E SOCIAL EM EXPERIÊNCIAS DE EXTENSÃO UNIVERSITÁRIA
}

\author{
JANIRA SODRÉ MirandA ${ }^{1}$ \\ ORCID: 0000-0003-1299-3794 \\ Eliani de Fátima Queiroz Covem ${ }^{2}$ \\ ORCID: 0000-0002-2310-9936 \\ Nicali Bleyer Ferreira dos Santos 3 \\ ORCID: 0000-0002-4800-7039 \\ Divino de Jesus da Silva Rodrigues ${ }^{4}$ \\ ORCID: 0000-0002-7661-1794
}

1 Historiadora, mestre em Ciência da Religião, professora do Instituto Federal de Educação, Ciência e Tecnologia de Goiás/Campus Goiânia. Assessora da Pró-Reitoria de Extensão e Apoio Estudantil da PUC Goiás. E-mail: (janirasodre@hotmail.com).

2 Jornalista, doutora em Sociologia, professora da Pontifícia Universidade Católica de Goiás da Escola de Comunicação (Curso de Jornalismo). Assessora de comunicação da Pró-Reitoria de Extensão e Apoio Estudantil da PUC Goiás. E-mail: (elianicovem@gmail.com).

3 Geógrafa, doutora em Ciências Ambientais, professora da Pontifícia Universidade Católica de Goiás da Escola de Formação de Professores e Humanidades (Curso de Geografia). Assessora da Pró-Reitoria de Extensão e Apoio Estudantil da PUC Goiás.E-mail: (nicalibleyer@hotmail.com).

4 Psicólogo, Pós-doutor em Psicologia, professor da Pontifícia Universidade Católica de Goiás (PUC Goiás) da Escola de Ciências Sociais e da Saúde (Curso de Psicologia). Assessor da Pró-Reitoria de Extensão e Apoio Estudantil da PUC Goiás. E-mail: (psico.divino@gmail.com). 
Resumo: O presente artigo apresenta ações extensionistas desenvolvidas pela Pró-Reitoria de Extensão e Apoio Estudantil, da Pontifícia Universidade Católica de Goiás, que buscam potencializar o protagonismo juvenil de acadêmicos e educandos por meio de práticas que visam à transformação da realidade social. A coleta de dados ocorreu por meio da pesquisa bibliográfica e documental, que subsidiaram a sistematização e análise das informações. Parte da contextualização do conceito de juventude e, após, apresenta ações desenvolvidas no Instituto Dom Fernando e seus programas. Os resultados apontam que a extensão universitária torna-se importante na formação e protagonismo juvenil, tanto para jovens acadêmicos quanto educandos envolvidos com as ações desenvolvidas, uma vez que proporciona um espaço para o enfrentamento de questões sociais, culturais, econômicas e políticas, desvelando a carência das políticas para juventude na esfera do poder público.

Palavras-chave: Extensão; juventude; universidade; protagonismo; cidadania.

Abstract: This article presents extension actions developed by the Dean of Extension and Student Support, of the Pontifical Catholic University of Goiás, which seek to enhance the youth role of academics and students through practices aimed at the transformation of social reality. The data collection occurred through bibliographic and documentary research, which subsidized the systematization and analysis of information. Part of the contextualization of the concept of youth and, after, present's actions developed at the Dom Fernando Institute and its programs. The results indicate that the university extension becomes important in the formation and youth protagonist, for young academics, as well as, students involved with the developed actions, since it provides a space for the confrontation of social, cultural, economic and political issues, unveiling the lack of youth policies in the sphere of public power.

Keywords: Extension; youth; university; protagonism; citizenship.

Resumen: El presente artículo presenta acciones de extensión desarrolladas por el Decano de Extensión y Apoyo Estudiantil, de la Pontificia Universidad Católica de Goiás, que buscan mejorar el protagonismo juvenil de académicos y estudiantes a través de prácticas destinadas a transformar la realidad social. La recolección de datos se realizó a través de la investigación bibliográfica y documental, que subsidió la sistematización y el análisis de la información. Parte de la contextualización del concepto de juventud y, luego, presenta acciones desarrolladas en el Instituto Dom Fernando y sus programas. Los resultados indican que la extensión universitaria se vuelve importante en la formación y el protagonismo juvenil, tanto para los jóvenes académicos como para los estudiantes, del grado secundario, involucrados en las acciones desarrolladas, puesto que proporciona un espacio para la confrontación de los problemas sociales, culturales, económicos y políticos, revelando la falta de políticas de juventud en el ámbito del poder público.

Palabras claves: Extensión; juventud; universidad; protagonismo; ciudadanía.

Submetido em: 22/08/2019.

Aceito em: 18/09/2019. 


\section{INTRODUÇÃO}

A extensão universitária, como propõe a Constituição Federal de 1988, em seu artigo 207, está vinculada à indissociabilidade entre o Ensino, a Pesquisa e a Extensão, de forma a integrar em suas ações a função acadêmica e formativa (BRASIL, 1988). Assim, a extensão como campo de estágio, de monitoria, e de trabalho voluntário, articula os saberes populares e acadêmicos e enriquece a formação humana e profissional dos sujeitos que atuam em seus programas e projetos.

Nessa perspectiva, a extensão não é vista apenas como prática meramente assistencialista, mas como uma parte importante no atendimento das necessidades sociais de uma comunidade. Jezine (2004) ressalta que a troca de conhecimentos promovida pelas ações extensionistas é benéfica tanto para a população atendida, quanto para os jovens acadêmicos inseridos nesse contexto formativo.

Nesse sentido, entendendo a extensão como um campo fértil e múltiplo de formação sócio-cultural e profissional, é possível perceber o protagonismo juvenil, tanto dos jovens acadêmicos, de variados extratos sociais, que atuam na extensão na qualidade de estagiários, monitores ou voluntários, potencializando a formação cidadã e a capacitação profissional para atuar em uma realidade complexa e desigual, quanto dos jovens educandos, que fazem parte dos programas extensionistas, que encontram nos projetos a oportunidade para potencializar a cidadania e o acesso a direitos sociais, atingidos por uma condição de vulnerabilidade política, social e econômica. Uma vez que estes se constituem nos principais atores desse cenário de aprendizagens múltiplas e constantes.

Ao optarem por desenvolver práticas de formação acadêmica nos programas e projetos de extensão, esses jovens acadêmicos estão optando também pelo desenvolvimento de uma formação humana e pluricultural, em um canal de diálogo que visa fortalecer o indivíduo, o sujeito social de direito.

Nesse locus de aprendizagem, onde os "diferentes jovens" se encontram é que a extensão torna-se parte fundante do protagonismo juvenil, uma vez que se proporciona um espaço para o enfrentamento de questões sociais, culturais, econômicas e políticas.

Cientes deste contexto este presente artigo apresenta ações extensionistas desenvolvidas pela Pró-Reitoria de Extensão e Apoio Estudantil (Proex), da Pontifícia Universidade Católica de Goiás (PUC Goiás), que buscam potencializar o protagonismo juvenil de acadêmicos e educandos por meio de práticas que visam transformar a realidade social. 
Nessa direção, inicialmente apresenta-se uma reflexão acerca do conceito de juventude como categoria social constituída na modernidade, para em seguida apontar as experiências de extensão na PUC Goiás, a partir do trabalho da juventude, que se constitui enquanto protagonista de seus projetos de vida e ação no mundo. Especificamente, são apresentados ações desenvolvidas no Instituto Dom Fernando e seus programas de extensão.

\section{JUVENTUDE - CATEGORIA SOCIAL E CULTURAL}

Parte-se da compreensão que a categoria juventude emerge enquanto processo constitutivo sócio-histórico e cultural junto às transformações que dão ensejo à modernidade. Nessa direção, segundo Weisheimer (2008), tomando por base os estudos de Ariès (1981), aponta que a emergência dessa ideia materializou-se a partir dos processos sociais ligados à instituição familiar e à classe social. A mudança na estrutura familiar, ocorrida ao longo do século XVII, evoluiu de extensa para nuclear. Isso porque as classes abastadas (aristocracia e burguesia) tinham a possibilidade de separar sua prole do convívio social e do mundo do trabalho para se dedicarem à vida adulta, por meio da escolarização. Essa última experiência é também ressaltada por Groppo (2000), ao indicar que a juventude foi primeiramente vivenciada pelas classes mais abastadas, para depois se ampliar, como categoria social válida, para os demais sujeitos sociais. Prática essa ainda comum nos dias atuais e que se materializa no contexto socioespacial antagônico de regiões menos favorecidas economicamente, onde a ação extensionista universitária, visando à formação cidadã, colabora para a convergência de um caminho único: o protagonismo juvenil.

Neste contexto, Abramo (1994), também se refere à obra de Ariès (1981) para sinalizar que o termo juventude esteve inicialmente relacionado a segmentos sociais que podiam realizar essa "suspensão social" de seus filhos, em vista de uma preparação para sua futura admissão na sociedade, assumindo os papéis sociais relacionados à vida adulta.

Também Weisheimer (2008), a partir das indicações retomadas de Ariés (1981), considera que o fenômeno de institucionalização e universalização do processo educacional, possibilitou a configuração e ampliação do conceito juventude na sociedade. Ao indicar a diversidade sócio-cultural da juventude, Groppo (2000, p.16) aponta uma ampliação temporal desta categoria, afirmando que "à juventude ideal e primitivamente construída - urbana, ocidental, branca e masculina - outras juventudes vieram (ou tentaram) juntar-se - rurais, não-ocidentais, negra, amarelas, mestiças, femininas". 
Assim, se inicialmente a juventude era tomada como fase de transição para a vida adulta e caracterizada pela vivência da moratória social oferecida a título de preparação aos papéis a serem assumidos na adultez, Abramo (2005) pondera que mudanças nas condições objetivas materiais de existência, relacionadas às transformações econômicas e sociais (mudanças no mundo do trabalho, no campo dos direitos e da cultura), assim como nas vivências dos próprios jovens (experiências e ações), provocaram uma "extensão da juventude, em vários sentidos: na duração desta etapa do ciclo da vida (...); na abrangência do fenômeno para vários setores sociais, (...); nos elementos constitutivos da experiência juvenil e nos conteúdos da noção socialmente estabelecida” (ABRAMO, 2005, p. 42).

Desse modo, para a autora, a juventude tem sido “(...) reconhecida como condição válida, que faz sentido, para todos os grupos sociais, embora apoiada sobre situações e significações diferentes" (ABRAMO, 2005, p. 44). Dessa maneira, reconhece-se a extensão universitária como palco de consolidação dessas diferentes juventudes, uma vez que articula os diferentes setores sociais, culturais, econômicos e de experiência juvenil, a partir de ações de formação acadêmico-cidadã e de empoderamento de jovens em situação de vulnerabilidade social.

Segundo Groppo (2016, p. 12), para "analisar as juventudes concretas, é preciso fazer o cruzamento da juventude - como categoria social - com outras categorias sociais e condicionantes históricos". Por conseguinte, Weisheimer (2008; 2013) busca delimitar teórico-operacionalmente as categorias: juventude, jovens, condição juvenil e situação juvenil, de tal forma, que é possível perceber uma relação diretamente proporcional entre os conceitos de juventude e condição juvenil, bem como de jovens e situação juvenil.

Nessa direção, Abramo (2005, p. 42) define que a condição juvenil é o “(...) modo como uma sociedade constitui e atribui significado a esse momento do ciclo da vida, que alcança uma abrangência social maior, referida a uma dimensão histórico geracional (...)” e situação juvenil é o “(...) o modo como tal condição é vivida a partir dos diversos recortes referidos às diferenças sociais - classe, gênero, etnia etc". Portanto, debruçar-se sobre a juventude, enquanto categoria social, possibilita entendê-la como uma criação dos sujeitos humanos, ou melhor, de uma dada estrutura social, no intuito de significar processos vivenciados dentro de determinada sociedade, escapando às compressões e delimitações já existentes nesse cenário.

Groppo (2000, p. 27) busca desnaturalizar a noção de juventude ao propor que os "grupos de idade são uma criação sócio-cultural própria, marcante e fundamental dos processos de modernização e da configuração das sociedades contemporâneas".

Assim, ao compreender a categoria juventude como processo constitutivo social, implica desnaturalizar concepções cristalizadas em torno dessa categoria, 
que a sociedade cunhou para estratificar parte do ciclo da vida e abre a possibilidade de relativizar e modificar as definições do que venha a ser "o jovem", bem como tensionar uma melhor compreensão desses como "sujeitos de direitos".

Em síntese, essas construções tratam-se "de representações simbólicas e situações sociais com suas próprias formas e conteúdos que têm importante influência nas sociedades modernas" (GROPPO, 2000, p. 8). Nesse sentido, as cristalizações das fases da vida são as formas que a sociedade produz para gerenciar a sua dinâmica social, para além das dinâmicas produzidas já pelas questões de raça, gênero, orientação sexual e de classes sociais.

Essa naturalização das etapas da vida está intimamente relacionada com as demais categorias sociais citadas, em um processo constante de interseccionalidade, gerando diferenciações de acesso e de poder social, ou melhor dizendo, criando subalternidades dentro da uma estrutura social vigente: capitalista e centrada no modelo adulto, masculino, heteronormativo e branco.

A cristalização das idades da vida é um fenômeno "social e histórico, datado", como Peralva (1997, p. 15) sinaliza. Portanto, partindo de um olhar sócio-histórico, pode-se afirmar que as representações sociais em torno dessas fases guardam as concepções presentes em uma dada sociedade em torno de cada categoria social etária. Tais concepções permeiam e produzem as práticas sociais voltadas para cada público e, consequentemente, engendra a constituição da própria subjetividade desses sujeitos destinatários, no caso específico aqui, das ações, projetos e programas (políticas públicas) voltados para a formação cidadã.

No que tange à juventude, Groppo (2000, p. 7) afirma que esta é uma concepção, "representação ou criação simbólica, fabricada pelos grupos sociais ou pelos próprios indivíduos tidos como jovens, para significar uma série de comportamentos e atitudes a ela atribuída. Ao mesmo tempo, é uma situação vivida em comum por certos indivíduos".

Ou ainda, que juventude é "uma categoria social usada para classificar indivíduos, normatizar comportamentos, definir direitos e deveres. É uma categoria que opera tanto no âmbito do imaginário social, quanto é um dos elementos "estruturantes" das redes de sociabilidade" (GROPPO, 2016, p.10).

A juventude é um construto social e cultural, que engendra práticas sociais voltadas ao trato com os sujeitos definidos como jovens, ao passo em que é geradora das subjetividades dos próprios sujeitos, que vivenciam o que essa categoria social demarca. De tal forma que os sujeitos, tidos como jovens, se comportarão e serão no mundo a partir das representações sociais a eles atribuídas (condição juvenil), vivenciando sua forma particular de ser jovem em uma dada realidade específica 
(situação juvenil), gerando novas representações ou reforçando as existentes, fortalecendo ou reconstruindo as concepções nucleadas em torno da própria categoria social juventude, em um processo dialético de constante transformação.

Ao longo do tempo, várias foram as nucleações de concepções para definir a juventude. Abramo (1994, p. 1) afirma que "refere-se a uma faixa de idade, um período da vida, em que se completa o desenvolvimento físico do indivíduo e uma série de mudanças psicológicas e sociais ocorre, quando este abandona a infância para processar a sua entrada no mundo adulto".

Groppo (2000, p. 18) aponta que idealmente, a juventude é tida como "uma fase transitória e de aquisição de maturidade social (...)", mas que esse ideal nem sempre corresponde com a realidade “(...) sócio-cultural múltipla e complexa”.

Já Alzipar e Bernal (2004), ao fazerem uma sistematização dos estudos da juventude, encontraram as seguintes categorias para definir essa condição social: a) juventude como etapa no desenvolvimento psico-biológico humano; b) juventude como momento chave para a integração social; c) juventude como dado sócio-demográfico; d) juventude como agente de mudança; e) juventude como problema do desenvolvimento; f) juventude e gerações; g) juventude como construção sócio-cultural.

Weisheimer (2008, p. 27) define a juventude como: "uma categoria social fundada em representações sociais segundo as quais se atribui sentido ao pertencimento a uma faixa etária, (...). A juventude é caracterizada ainda pelo processo contínuo de socialização, o que configura a transição da infância à vida adulta”.

Tanto Abramo (1994), como Groppo (2000) e Weisheimer (2008), ainda que problematizem a naturalização das conceituações da juventude na modernidade e a necessidade de compreender as várias juventudes existentes, nucleiam a definição de juventude na perspectiva da transitoriedade e inserção desses sujeitos à vida adulta. Talvez este fenômeno esteja relacionado à tentativa de delimitar uma construção simbólica e etária para a juventude, ou seja, um esforço no sentido de categorizar a condição juvenil, com certa objetivação, em fatores variáveis, mas classificáveis social e cronologicamente. Ao mesmo tempo, essas conceituações revelam elementos fundantes da atual estrutura social, marcadamente adultocêntrica e que, consequentemente, deslegitimam a potencialidade dos jovens como atores sociais, com protagonismo e demandas diversas, para além de se preparar para a vida adulta, não os reconhecendo, dessa forma, como sujeitos de direitos.

A partir desta historicidade do processo constitutivo da categoria juventude, é importante esclarecer que não se pretende fazer uma explanação desses contextos no presente texto, antes, a ideia aqui é apenas considerar as diferentes concepções de juventudes gestadas na sociedade para problematizarmos a instrumentalização 
dessas concepções nas ações extensionistas e produção das agências juvenis, compreendidas enquanto possibilidades de uso da liberdade para constituir a juventude enquanto sujeito de seu próprio devir no mundo.

A importância de considerar a juventude como construção social demonstra que as concepções destinadas a essa categoria não são de ordem natural, podendo sofrer e, de fato, sofrendo modificações ao longo do tempo histórico; como também permite que novas áreas da ciência sejam criadas para estudar e compreender as transformações no campo do simbólico (condição juvenil) e no campo das vivências cotidianas (situação juvenil). No que se refere a essas vivências, destaca-se o papel de programas permanentes de extensão que, por meio de diversas atividades, permitem o contato diário e a sensibilidade cotidiana do fazer e do aprender, possibilitando um perene diálogo entre a teoria e a prática no contexto formativo.

Nesse sentido, a extensão universitária, ao promover o diálogo entre as diferentes "juventudes", atua na problematização social da construção identitária de um sujeito geracional: o jovem cidadão com desejos, conflitos sociais, diferenças culturais e busca de constituição de seu projeto de vida afetiva e profissional. Ao unir em suas práticas o jovem acadêmico e o jovem educando, os programas de extensão evidenciam que, embora existam diferenças socioculturais e econômicas, conflui a experiência geracional relacionada aos projetos comuns à juventude como grupo social, o que contribui para a desmistificação da extensão como ação meramente solidária e/ou de prestação de serviços.

Doutra parte é importante destacar a visão de extensão, estabelecida pela PUC Goiás em sua Política de Extensão (2006), que a concebe como processo acadêmico articulado ao compromisso com a qualidade social da formação acadêmico-científica, relacionando suas ações aos grandes temas sócio-políticos e culturais junto ao processo formativo de seus acadêmicos. O referido documento aponta ainda que a extensão universitária deve objetivar a superação e a distinção das perspectivas que limitam a Extensão à mera prestação de serviços, à transferência de conhecimentos e à difusão cultural (UNIVERSIDADE CATÓLICA DE GOIÁS, 2006).

\section{INSTITUTO DOM FERNANDO (IDF) - ESPAÇO EXTENSIONISTA DE FORMAÇÃO ACADÊMICA E CIDADÃ.}

A partir dessa contextualização supra-mencionada, que aponta as conceituações pelas quais a juventude foi sendo definida ou delimitada na sociedade e no campo acadêmico, percebe-se que a juventude é uma categoria social e cultural. 
Sendo esta concepção acerca da juventude que alicerça o desenvolvimento de ações extensionistas promovidas pela PUC Goiás, que por intermédio do Instituto Dom Fernando - IDF visam potencializar a formação dos jovens, tanto acadêmicos, na qualidade de voluntários, monitores e estagiários, quanto educandos na posição de partícipes dos projetos permanentes de extensão.

O Instituto Dom Fernando foi criado em março de 1995 pela Sociedade Goiana de Cultura, na condição de mantida. Desde 2006, este Instituto passou a ser uma unidade acadêmico-administrativa vinculada à Pró Reitoria de Extensão e Apoio Estudantil da PUC Goiás. Suas ações extensionistas buscam: "proporcionar ferramentas para que os sujeitos em situação de vulnerabilidade possam exercer suas funções de cidadãos, incentivando o protagonismo nos campos político, social e cultural" (PONTIFÍCIA UNIVERSIDADE CATÓLICA DE GOIÁS, 2017, p. 60).

Fazem parte do IDF o Centro de Estudo, Pesquisa e Extensão Aldeia Juvenil (CEPAJ), o Centro de Educação Comunitária de Meninas e Meninos (CECOM), a Escola de Formação da Juventude (EFJ) e a Escola de Circo Dom Fenando (ECDF). Em todos esses espaços, as estratégias didáticas e formativas são voltadas para a superação psicossocial e profissional de jovens residentes em comunidades carentes, localizadas em bairros periféricos da cidade de Goiânia, Goiás. Nesses locais são oferecidos cursos profissionalizantes e formativos, palestras, oficinas, brincadeiras educativas lúdicas e acompanhamento psicológico especializado.

Nos programas de extensão os jovens têm sua autoestima fortalecida e são incentivados a transformar sua situação cultural, social e econômica. Atuam nesses processos uma grande diversidade de atores sociais, como funcionários e professores da PUC da Goiás, voluntários, parceiros de outras instituições ou órgãos governamentais e jovens acadêmicos graduandos da PUC Goiás e de outras Universidades. Apresenta-se, a seguir, os programas do IDF.

\section{CENTRO DE ESTUDO, PESQUISA E EXTENSÃO ALDEIA JUVENIL (CEPAJ)}

Fundado em 1983, na Região Noroeste de Goiânia, o CEPAJ realiza ações socioeducativas voltadas à prevenção de violência, especialmente contra os jovens. Ações que materializam-se por meio de atendimentos, oficinas, articulações junto aos movimentos sociais e populares, bem como intervenção nas escolas e instituições locais, com ênfase na promoção, garantia e defesa dos direitos humanos.

Nessa direção, os atendimentos psicossociais têm por objetivo potencializar a qualidade de vida dos sujeitos, promovendo saúde e autoconhecimento, que vão 
além do atendimento aos jovens, atendendo também às suas famílias. O Projeto Comunicar, vinculado à área de Fonoaudiologia, busca transformar a realidade dos jovens para maior integração à comunidade pelo uso da linguagem oral e escrita. Esses atendimentos são realizados individualmente ou em grupo, utilizando estratégias como dramatização, jogos educativos, entre outras técnicas psicológicas e do campo da fonoaudiologia.

O Projeto Minha Casa, Extensão da Minha Escola visa estimular o fortalecimento dos vínculos familiares, pelo hábito da leitura em família, contribuindo para o processo de ensino aprendizagem, especialmente dos jovens, por meio de uma orientação socioeducativa a partir de uma perspectiva inter e transdisciplinar.

As Oficinas e Grupos Sócio-Psico-Educativos trabalham temáticas de interesse comum dos jovens. Possuem perspectiva informativa e oferecem suporte emocional aos participantes, criando um espaço de acolhimento das expressões emocionais, contribuindo para a descoberta de novas formas de agir e reagir diante das experiências vivenciais do cotidiano dos jovens.

O Projeto de Orientação e Apoio Familiar é destinado às famílias dos jovens participantes e oferece apoio e informações acerca de direitos e deveres da pessoa. Além das orientações, o projeto faz encaminhamentos a equipamentos sociais especiais, no caso de necessidades específicas de acompanhamento.

Ainda na direção das ações extensionistas do CEPAJ, ressalta-se o Projeto Brincando com os Livros, que trabalha a leitura de forma lúdica, incentivando os jovens a praticarem a leitura no sentido de ampliar conhecimentos e fortalecer vínculos. Faz parte também desse projeto, o empréstimo de livros aos educandos, de modo a ampliar o universo de leitura para além dos muros do CEPAJ. Também é feito o empréstimo de livros na busca de formação de leitores críticos da realidade, com caráter informativo, associado ao despertar do prazer pela leitura.

\section{CENTRO DE EDUCAÇÃO COMUNITÁRIA DE MENINAS E MENINOS (CECOM)}

Espaço de convivência comunitária, dedicado à promoção da cidadania, o CECOM está localizado na periferia da cidade de Goiânia, sendo referência de apoio, entre outros, aos bairros das regiões Mendanha e Noroeste e dos municípios vizinhos. Foi fundado em 1984.

As ações extensionistas desenvolvidas pelo CECOM compreendem a questão da juventude em suas diferentes manifestações, desenvolvendo atividades por meio de diversos programas, com o propósito de subsidiar intervenções e de colaborar com a proposição de políticas públicas voltadas para esse segmento social. 
Os jovens matriculados na Escola Direito do Saber, do Ensino Fundamental, em parceria com a Secretaria Municipal de Educação, participam da Oficina Criança Dança e do Laboratório Digital “O mundo na ponta dos dedos”. Assim, busca-se propiciar o exercício da cidadania por meio de atividades pedagógicas que garantam a permanência escolar, oportunizando a inclusão digital e a integração cultural entre os educandos.

Na direção da empregabilidade para os jovens, o CECOM conta com a Associação de Apoio aos Desempregados (Asdag), as Oficinas de Higiene e Beleza, de Panificação e Confeitaria e Profissionalizante de Costura Industrial. Essas ações oportunizam que diversos jovens se profissionalizem para a entrada no mundo do trabalho.

Em relação às questões de tutela jurisdicional, o CECOM - por meio do Núcleo de Apoio Jurídico ao Cidadão (NAJUC) - contribui para o reconhecimento das pessoas, especialmente dos jovens, como cidadãos de sujeitos de direitos, apoiando juridicamente quando esses direitos são ameaçados ou violados.

O CECOM desenvolve também um trabalho de capacitação de conselheiros tutelares e de direitos, contribuindo com a capacitação para o exercício das responsabilidades na promoção, defesa e garantia dos direitos humanos fundamentais da criança, do adolescente e de jovens à luz de tratados, convenções internacionais e legislação brasileira.

Outro programa de destaque no CECOM é o Serviço de Convivência e Fortalecimento de Vínculos. As intervenções, especialmente junto aos jovens, são realizadas por meio de experiências lúdicas, culturais e esportivas como forma de expressão, interação, aprendizagem, sociabilidade e proteção social.

O Centro recebe ainda crianças, adolescentes e jovens, com deficiência ou não, retirados de trabalhos proibidos por lei ou submetidos a outras violações, que são incluídos em atividades que contribuem para ressignificar vivências de isolamento e de violação de direitos, além de proporcionar experiências que favoreçam o desenvolvimento de sociabilidades. O trabalho de proteção social básica desenvolvido pelo CECOM tem como objetivo prevenir situações de risco social por meio do desenvolvimento das potencialidades coletivas; e o fortalecimento de vínculos familiares e comunitários.

\section{ESCOLA DE FORMAÇÃO DA JUVENTUDE (EFJ)}

As práticas extensionistas desenvolvidas pela EFJ constituem-se de atividades que contribuem para o pleno exercício da cidadania, protagonismo juvenil, inclusão social e qualificação profissional da juventude. A Escola, que foi fundada em 1995, está localizada no Jardim Dom Fernando I, zona periférica da capital 
goiana e é tida como referência pelos jovens da região. As ações da Escola têm na cultura local o ponto de partida para o diálogo e a formação juvenil, buscando contribuir tanto nos aspectos relacionados à sociabilidade juvenil quanto ao mundo do trabalho, garantia dos direitos, promoção, prevenção e cuidados com a saúde e bem-estar.

No processo de execução das ações extensionistas, a Escola alicerça-se em três eixos que norteiam a didática, a prática e a metodologia no desenvolvimento de seus diversos projetos, sendo eles: formação política, profissional e cultural. No eixo da formação política, os trabalhos na Escola são realizados por meio da elaboração e execução de programas e projetos que levem os jovens à ação e reflexão das mudanças ocorridas no mundo contemporâneo, nos aspectos produtivos, tecnológicos, políticos e simbólicos, tendo como referência as experiências de educação popular, dando destaque à relação dos homens e mulheres com o mundo do trabalho, inovações no campo da produção, cidadania e a sociabilidade juvenil.

No eixo da formação profissional, na perspectiva da empregabilidade, grande desafio deste segmento da sociedade, a Escola oferece cursos de Auxiliar Administrativo e Inglês Básico. Em parceria com o Departamento de Computação da PUC Goiás, oferece também cursos de Informática, Nível Básico, Intermediário e Avançado.

Ainda, na perspectiva do eixo da cultura como elemento de direito social, oferece a Oficina de Teatro. Nessa direção, a Escola desenvolve também diversos projetos, como o Projeto de Vida, Escola Integrada, Integra Mais e Interagir. Todos esses projetos têm por objetivo formar para o exercício da cidadania e do protagonismo dos jovens, com uma leitura crítica da realidade social que estão inseridos. Ainda neste conjunto de ações busca-se também desenvolver ações que objetivam a aproximação e o envolvimento da comunidade e das famílias dos jovens.

É importante ressaltar que, deste a fundação, a Escola é um espaço que propicia um local de diálogo, de prática de estágio supervisionado, e de desenvolvimento de pesquisa, para várias áreas das Ciências Humanas e Sociais que tenham como foco de suas investigações a temática da juventude. Alguns alunos da PUC Goiás realizaram o Trabalho de Conclusão de Curso (TCC) tendo como temática as atividades desenvolvidas na Escola. Inclusive a banca avaliadora desses trabalhos foi realizada na própria Escola, com autorização da coordenação do curso correspondente.

\section{ESCOLA DE CIRCO DOM FERNANDO (ECDF)}

As ações extensionistas da Escola de Circo Dom Fernando - ECDF buscam contribuir com a construção da cidadania de jovens em situação de vulnerabilidade 
social. Está localizada na Região Leste de Goiânia, também no Jardim Dom Fernando I, e foi fundada em 1996. A Escola de Circo atende por semestre, em média, 110 crianças e adolescentes, com idades entre sete e dezesseis anos.

A proposta pedagógica da Escola de Circo é inspirada nos princípios metodológicos do Circo Social, nos quais a integração das dimensões lúdicas, cognitivas, afetivas, emocionais e sociais são efetivadas na execução de oficinas circenses, de jogos, brincadeiras populares, iniciação esportiva, da prática da capoeira e de atividades reflexivas. Desenvolvidas de forma conjunta, com a prática se unindo à reflexão de cada ação, essas metodologias buscam superar as desigualdades sociais da região, por meio da integração dos educandos às práticas socioculturais, como protagonistas.

As ações da Escola de Circo conseguem envolver toda a comunidade. Isso é possível em função da interlocução constante que ocorre nas ações, festividades e apresentações circenses. Com essa prática, que visa promover a integração social e familiar, a Escola busca a construção de uma nova forma de ver o mundo, onde a metodologia do Circo Social é utilizada como instrumento facilitador da construção do protagonismo juvenil, trazendo a percepção e a cultura do espaço de vivência dos educandos como instrumento de empoderamento social para as famílias da região.

Nesse contexto, cabe destacar a importância da Escola de Circo estar vinculada a uma instituição de ensino superior, uma vez que promove o acesso à informação produzida na academia e que transcende os muros da universidade, abrindo a oportunidade das trocas perenes dos conhecimentos formais e não formais, em uma via de mão dupla, aproximando a comunidade e a universidade em ações que possibilitam o constante crescimento de ambos.

A Escola de Circo é importante como campo de formação acadêmica de diferentes cursos, unindo a teoria e a prática por meio da materialização de um trabalho sociocultural, constituindo-se em campo de estágio curricular e voluntário, para os acadêmicos de cursos da própria instituição como o Direto, a Psicologia, a Educação Física e o Serviço Social e de outras instituições. Essa prática amplia o contato dos educandos com diferentes cursos de formação, ampliando a possibilidade de diálogo e formação cidadã para os diferentes atores envolvidos nas práticas cotidianas da Escola de Circo.

\section{CONSIDERAÇÕES FINAIS}

Em suma, ao apresentar as ações extensionistas executadas pelo Instituto Dom Fernando (PUC Goiás), articuladas aos conceitos e historicidade relacionadas ao tema juventude, o presente estudo objetivou contribuir com as discussões acerca 
do local de formação que a extensão universitária ocupa junto aos jovens, uma vez que é palco da manifestação de aprendizagens múltiplas e superação de desigualdades sociais, culturais e econômicas.

Constatando-se inicialmente que, em sua gênese, a categoria social juventude se constituiu num recorte de classe que se alimenta das possibilidades oferecidas às camadas altas da sociedade, percebe-se a extensão como um local onde as diferentes juventudes, com suas respectivas experiências e histórias de vida, podem partilhar simultaneamente de momentos formativos e de aprendizagem, tornando-se protagonistas de seu processo de formação e qualificação. Nesses espaços, acadêmicos e educandos partilham uma formação humanística, essencial ao desempenho profissional futuro. Como campo de monitoria, estágio e voluntariado a extensão se articula ao Ensino e à Pesquisa, se consolidando como campo acadêmico, de interface com a comunidade, potencializando a qualidade social do ensino.

A despeito dos avanços e do acúmulo produzidos pela Política de Extensão da PUC Goiás, considera-se ainda o desafio de inserir maiores contingentes juvenis junto aos programas extensionistas, de modo a ampliar a participação discente. Ações como a campanha de voluntariado vêm sendo implementadas no sentido de ampliar o número de graduandos na extensão na PUC Goiás, conseguido uma boa resposta dos acadêmicos. Atualmente cerca de seiscentos estudantes atuam, todo semestre, em diversos programas extensionistas da universidade, de forma voluntária.

No que se refere aos jovens educandos, cabe destacar que a procura pelas ações desenvolvidas pelo Instituto Dom Fernando revela a carência das políticas para juventude na esfera do poder público. Vez que, apesar de significativos avanços em instrumentos legais, como o Estatuto da Juventude, ainda é modesto o avanço no campo das políticas vigentes nas pautas da juventude de fato implementadas.

Assim, percebe-se que o esforço em pesquisar e desenvolver ações extensionistas para jovens depara-se com a necessidade de compreender o percurso histórico e as construções sociais que foram agregadas e nucleadas em torno da categoria juventude. Contudo, os limites e necessidades de operacionalização acadêmica demandam uma definição válida para a situação juvenil, especificamente a juventude pobre, das periferias das cidades brasileiras, que apontem para a autonomia e transformação da realidade social desses sujeitos.

Desta maneira, têm-se ciência da colaboração dessas ações para potencializar o protagonismo juvenil, em vista da autonomia e exercício da cidadania em direção da garantia dos direitos da juventude. Nesse sentido, é necessário superar essas visões, e colocar de fato a pauta das juventudes, principalmente a juventude empobrecida, no bojo das políticas públicas que articulam as dimensões de educação, lazer e trabalho para a totalidade dos jovens brasileiros. 


\section{REFERÊNCIAS}

ALPIZAR, Lydia; BERNAL, Marina. Construção Social da Juventude. In: Manual de capacitação em direitos humanos das mulheres jovens e aplicação da CEDAW. Rede Latino Americana e Caribenha de Jovens por Direitos Sexuais e Reprodutivos - REDLAC e pelo Programa Mulher, Justiça e Gênero - ILANUD. Edição Brasileira: Fundo de Populações das Nações Unidas UNFPA. p.21-35. 2004, Disponível em https://www.academia.edu/11643621/ Construção_social_da_juventude. Acesso em: 25 ago. 2019.

ARIĖS, Philippe. História social da criança e da família. Trad. Dora Flaksman. Rio de Janeiro: Zahar Editores, 1981.

ABRAMO, Helena Wendel. Cenas juvenis: punks e darks, no espetáculo urbano. São Paulo: Página Aberta, 1994.

. O uso das noções de adolescência e juventude no contexto brasileiro. In: FREITAS, Maria Virgínia (org.). Juventude e adolescência no Brasil: referências conceituais. São Paulo: Ação Educativa, 2005, p. 19-35.

BRASIL. Constituição Federal de 05 de outubro de 1988. Constituição da República Federativa do Brasil. Brasília: Senado Federal, 1988. Disponível em: http://www.planalto.gov.br/ccivil_03/constituicao/constituicaocompilado. htm. Acesso em: 14 set. 2019.

GROPPO, Luís Antônio. Juventude: ensaios sobre sociologia e história das juventudes modernas. Rio do Janeiro: Difel, 2000.

. Juventudes: sociologia, cultura e movimentos. Alfenas: Universidade Federal de Alfenas, 2016.

JEZINE, Edineide. As práticas curriculares e a extensão universitária. In: CONGRESSO BRASILEIRO DE EXTENSÃO UNIVERSITÁRIA, 2º, 2004, Belo Horizonte. Anais. Belo Horizonte: Universidade Federal da Paraíba (UFPB), 2004. 1-6. 
PERALVA, Angelina. O jovem como modelo cultural. Revista Brasileira de Educação, São Paulo, ANPED, n. 5-6, maio-dez. p. 15-24. 1997. Disponível em: http://anped.tempsite.ws/novo_portal/rbe/rbedigital/RBDE05_6/ RBDE05_6_04_ANGELINA_PERALVA.pdf. Acesso em: 15 set. 2019.

PONTIFÍCIA UNIVERSIDADE CATÓLICA DE GOIÁS. Plano de Desenvolvimento Institucional. PUC Goiás, 2017.

WEISHEIMER, Nilson. A construção social da juventude. In: Universidade Luterana do Brasil. Sociologia da Juventude. Curitiba: Ipbex, 2008, p. 15-32.

Apontamentos para uma sociologia da juventude. Revista Cabo-verdiana de Ciências Sociais, Cabo Verde, ano 1, n. 1, jan.-dez. p. 09-26, 2013. Disponível em: https://www.academia.edu/7146270/Revista_Cabo-verdiana_ de_Ciencias_Sociais_-_Juventudes. Acesso em: 15 set. 2019.

UNIVERSIDADE CATÓLICA DE GOIÁS, Política de Extensão. Goiânia: Ed. da UCG, 2006. 